\title{
Relationship Between Body Mass Index and Dental Age in 8-15- Year-Old Orthodontic Patients
}

\author{
Eka Erwansyah ${ }^{1}\left[\right.$, Susilowati Mudjari ${ }^{1}\left[\right.$, Fuad Husain Akbar ${ }^{\circledR}$, Adrian Rustam ${ }^{3}$
}

\begin{abstract}
${ }^{1}$ Department of Orthodontics, Faculty of Dentistry, Hasanuddin University, Kota Makassar, Indonesia.
${ }^{2}$ Department Dental Public Health, Faculty of Dentistry, Hasanuddin University, Kota Makassar, Indonesia.

${ }^{3}$ Dental Hospital, Faculty of Dentistry, Hasanuddin University, Kota Makassar, Indonesia.
\end{abstract}

Author to whom correspondence should be addressed: Eka Erwansyah, Department of Orthodontics, Faculty of Dentistry, Hasanuddin University, Jl. Perintis Kemerdekaan KM.10, Tamalanrea Indah, Kec. Tamalanrea, Kota Makassar, Sulawesi Selatan 90245, Indonesia. Phone: +62 811414098. E-mail: eka_ortho@yahoo.com.

Academic Editors: Alessandro Leite Cavalcanti and Wilton Wilney Nascimento Padilha

Received: 22 May 2019 / Accepted: 13 February 2020 / Published: 07 April 2020

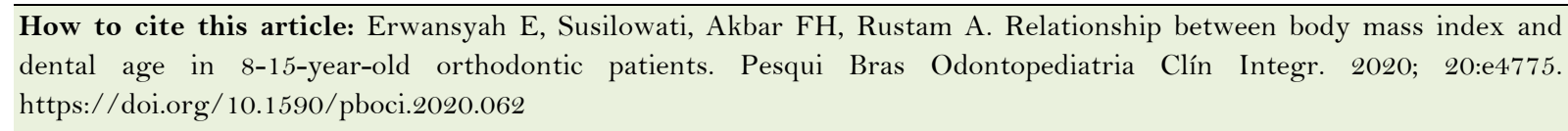

\begin{abstract}
Objective: To investigate the relationship between Body Mass Index (BMI) and dental age in 8-15-yearold orthodontic patients. Material and Methods: Forty-eight children (25 males, 23 females) aged 8-15 years requiring orthodontic treatment participated in this retrospective study. The dental development ages were determined using the Demirjian method and panoramic radiographs. Afterwards, chronological age, height, and weight were recorded. Using the standard equation developed by the Center for Disease Control and Prevention, BMI value was calculated and grouped according to BMI percentile classification according to age and gender. Data were analyzed using the Pearson correlation test. The level of significance was set at $\mathrm{p}<0.05$. Results: Dental age was significantly accelerated in subjects with increased BMI percentile after adjusting for age and gender $(\mathrm{p}<0.05)$. The mean dental age among all subjects was $10.58 \pm 2.40$. The correlation coefficient ( $\mathrm{r}$ ) showed a strong correlation with a positive direction, which means that the dental age also accelerated by $44.6 \%$ in the subjects with increased BMI. Conclusion: There was a linear correlation between increased BMI with accelerated dental age. BMI value and dental age can be considered in determining orthodontic treatment time.
\end{abstract}

Keywords: Orthodontics; Radiography, Dental; Anthropometry; Body Mass Index. 


\section{Introduction}

The growth and development stages of patients during mixed dentition is crucial to understand by orthodontist. Data regarding active facial growth (growth spurt) may assist the orthodontist in determining a treatment plan particularly appropriate initial time of orthodontic treatment. The entry time of the growth spurt period can be determined by predicting maturation stages accurately and appropriately [1].

Generally, the parameter used in determining maturation stage is chronological age, which is assessed according to date, month and year of birth [2]. However, a chronological age provided less precise information about human growth making it less effective to be used as a maturation assessment parameter. Therefore, a more proper maturation assessment through other parameters such as biological age has been recommended $[3,4]$.

Dental age as one of biological age indicator has been of particular interest to orthodontists since it is still the most effective and accurate indices in assessing craniofacial development stages [5]. Dental maturity determined based on the tooth calcification stages has been proposed as a more reliable criterion rather than tooth eruption stages because it exhibits less variability and is less affected by environmental factors. Previous authors formulated the method of dental age assessment by reference to the radiological appearances of the seven teeth on the left side of the mandible [6]. However, dental maturity indicator is multifactorial. Recent studies suggest that Body Mass Index (BMI) is one of the significant factors suspected to affect the occurrence of dental age variations [7].

Several studies have validated that obese adolescents tend to experience early craniofacial growth and development than their normal BMI peers. These findings indicated that nutrition status may correlate to dental maturation [8,9]. In other studies, no correlation was found between the two variables [10,11].

Recently, the rates of malnutrition in the Indonesian population have been increasing among both children and adults. In 2013 the percentage of obesity and underweight people in 21 provinces was still above the national standard average (5.4\%). The incidence of undernutrition is increasing every year by $18.4 \%$ while for obesity by $16 \%$. The dramatic and widespread increase in the prevalence of malnutrition in Indonesia could have an impact on the demographics of the average orthodontic practice [12].

No previous study has evaluated the effect of BMI on dental age, especially in Indonesia. Therefore, the purpose of this study was to investigate the relationship between BMI and dental age in 8-15-year-old orthodontic patients.

\section{Material and Methods}

Study Design

This research was designed as a cross-sectional descriptive study and was conducted between MayJune 2015 in three dental clinics: Eka Erwansyah Clinical Orthodontics Center, Dentamedica Care Center Clinic and Dental Hospital of Hasanuddin University, South Sulawesi, Indonesia.

Sample

The samples consisted of 48 patients (25 males, 23 females) between 8-15 years of age requiring orthodontic treatment. The subjects were purposively selected based on the inclusion criteria as follows: 1) No history of extraction of any permanent teeth; 2) No presence of dental anomaly such as agenesis; 3) Subjects will undergo orthodontic treatment in 2015; and 4) Pretreatment panoramic radiographs of adequate 
diagnostic quality were taken within one month. Exclusion criteria were: 1) subjects have no history of the systemic diseases; 2) tooth was not completely or clearly visible on the panoramic radiographs; and 3) any presence of congenital tooth anomalies.

\section{Data Collection}

The measured variables comprised of dental age and Body Mass Index percentile. The pretreatment panoramic radiographs were assessed on the box tracing by a single investigator independently from their BMI data. Dental calcification stages, dental maturity score, and corresponding dental age were determined according to the method described by Demirjian (Table 1). Using this protocol, seven mandibular teeth (left central incisor to left second molar) were scored based on eight stages of dental calcification [6]. Scoring was based on the criterion from crown calcification, root development, and apex characteristics. After that, the scores were added together to give a dental maturity reading and then converted to a dental age using a gender-specific table.

Table 1. Scores for dental maturation stages seven teeth (mandibular left side) [6].

\begin{tabular}{|c|c|c|c|c|c|c|c|c|c|}
\hline \multirow{3}{*}{ Tooth } & \multicolumn{9}{|c|}{ Boys } \\
\hline & \multicolumn{9}{|c|}{ Stage } \\
\hline & $\mathrm{O}$ & A & B & $\mathrm{C}$ & $\mathrm{D}$ & $\mathrm{E}$ & $\mathrm{F}$ & G & $\mathrm{H}$ \\
\hline $\mathrm{M} 2$ & 0.0 & 2.1 & 3.5 & 5.9 & 10.1 & 12.5 & 13.2 & 13.6 & 15.4 \\
\hline M1 & & & & 0.0 & 8.0 & 9.6 & 12.3 & 17.0 & 19.3 \\
\hline $\mathrm{P} 2$ & 0.0 & 1.7 & 3.1 & 5.4 & 9.7 & 12.0 & 12.8 & 13.2 & 14.4 \\
\hline $\mathrm{P} 1$ & & & 0.0 & 3.4 & 7.0 & 11.0 & 12.3 & 12.7 & 13.5 \\
\hline $\mathrm{C}$ & & & & 0.0 & 3.5 & 7.9 & 10.0 & 11.0 & 11.9 \\
\hline $\mathrm{I} 2$ & & & & 0.0 & 3.2 & 5.2 & 7.8 & 11.7 & 13.7 \\
\hline I 1 & & & & & 0.0 & 1.9 & 4.1 & 8.2 & 11.8 \\
\hline \multirow{3}{*}{ Tooth } & \multicolumn{9}{|c|}{ Girls } \\
\hline & & & & & Stage & & & & \\
\hline & $\mathrm{O}$ & $\mathrm{A}$ & B & $\mathrm{C}$ & $\mathrm{D}$ & $\mathrm{E}$ & $\mathrm{F}$ & G & $\mathrm{H}$ \\
\hline $\mathrm{M} 2$ & 0.0 & 2.7 & 3.9 & 6.9 & 11.1 & 13.5 & 14.2 & 14.5 & 15.6 \\
\hline M1 & & & & 0.0 & 4.5 & 6.2 & 9.0 & 14.0 & 16.2 \\
\hline $\mathrm{P} 2$ & 0.0 & 1.8 & 3.4 & 6.5 & 10.6 & 12.7 & 13.5 & 13.8 & 14.6 \\
\hline $\mathrm{P} 1$ & & & 0.0 & 3.7 & 7.5 & 11.8 & 13.1 & 13.4 & 14.1 \\
\hline $\mathrm{C}$ & & & & 0.0 & 3.8 & 7.3 & 10.3 & 11.6 & 12.4 \\
\hline $\mathrm{I} 2$ & & & & 0.0 & 3.2 & 5.6 & 8.0 & 12.2 & 14.2 \\
\hline I 1 & & & & & 0.0 & 2.4 & 5.1 & 9.3 & 12.9 \\
\hline
\end{tabular}

The Body Mass Index was calculated by dividing weight $(\mathrm{kg})$ by height squared $\left(\mathrm{m}^{2}\right)$ and then BMI percentiles were assessed using specific BMI percentile charts for age and gender produced by the Center of Disease Control and Prevention (CDC). A child with a BMI percentile $<5$ th is considered underweight, 5th85 th percentile is normal weight, 85 th-95th is overweight, and 95 th or greater is obese.

Data Analysis

All data were statistically analyzed and organized by using SPSS 18.0 software. Normality distribution of samples was analyzed using Shapiro-Wilk test. Pearson correlation test was performed to determine the relationship between variables (dental age and Body Mass Index), the direction and magnitude of the relationship between the two variables. The level of significance was set at $\mathrm{p}<0.05$. 


\section{Ethical Aspects}

Before starting, the study protocol was approved by the Medical Faculty Ethics Committee of Hasanuddin University (1007 / H4.8.4.5.31 / PP36-KOMETIK / 2015). Explanation of the study purpose and method was given to all patients and/or their parents and informed consent was obtained from all subjects.

\section{Results}

Forty-eight children consisting of 25 males (52.1\%) and 23 women (47.9\%) met all inclusion criteria and were included in the study (Table 2 ). The mean chronological ages was $10.43 \pm 2.25$ years, with the mean dental age and BMI respectively was $10.58 \pm 2.40$ and $17.38 \pm 4.29$. The mean body weight and height was 32 $\mathrm{kg}$ and $132 \mathrm{~cm}$. Of the 48 samples, 15 (31.3\%) were underweight, 19 samples (39.6\%) were normal, 7 samples (14.6\%) were overweight, and 7 samples (14.6\%) were obese, according to the CDC's standard for children.

Table 2. Distribution of study sample characteristics.

\begin{tabular}{lccc}
\hline \multicolumn{1}{c}{ Variables } & N & $(\%)$ & Mean (SD) \\
\hline Gender & 25 & 52.1 & \\
Boys & 23 & 47.9 & \\
Girls & & & $10.43 \pm 2.25$ \\
Chronological Age & 26 & 54.2 & \\
8-10 years old & 9 & 18.8 & \\
10-12 years old & 13 & 27.1 & \\
12-15 years old & & & $10.58 \pm 2.40$ \\
Dental Age & 15 & 31.3 & \\
7-9 years old & 16 & 33.3 & \\
9-11 years old & 8 & 16.7 & \\
11-13 years old & 9 & 18.8 & $1.98 \pm 14.00$ \\
13-15 years old & & & \\
Body Weight (kg) & & & \\
Body Height (cm) & & & \\
Body Mass Index (BMI) & 15 & 31.3 & \\
Underweight & 19 & 39.6 & 15.44 \\
Normal / Ideal & 7 & 14.6 & \\
Overweight & 7 & 14.6 & \\
Obese & 48 & 100.0 & \\
$\quad$ Total & & & \\
\hline
\end{tabular}

The mean distribution of dental age and BMI based on gender, chronological age, and BMI categories. The mean BMI value of females was $17.77 \pm 4.72$ with the mean dental age was $10.60 \pm 2.44$, whereas the mean BMI value of males was $17.02 \pm 3.92$ followed by mean dental age with $10.57 \pm 2.42$ (Table 3). Based on chronological age, it appears that the highest dental age and BMI values found in 12-15 years of age group. Subjects included in the 7-9 years of dental age group have an average BMI value of 14.7, while in the 13-15 years of dental age group, the average BMI value was 21.58. The obese group had an average dental age up to 12 years, while the underweight group was only nine years.

Pearson correlation test showed significant values $(\mathrm{p}<0.05)$ in all age groups, indicating that there was a significant correlation between Body Mass Index with dental age for 8-10, 10-12 and 12-15 years old (Table 4). The correlation coefficient ( $r$ ) value showed a significantly strong correlation with a positive direction. This was described further in the coefficient of determination value (r2). When evaluating for statistical significance, as BMI increased, dental age was more advanced, $53.8 \%$ in $8-10$ age group, $84.6 \%$ in $10-12$ age group, and 
$36.3 \%$ in $12-15$ age group. Overall, statistical tests results also showed a significant correlation between BMI values with dental age in which the dental age was more advanced, $44.6 \%$ as the BMI increased $(p<0.001)$.

Table 3. Mean distribution of dental age and BMI value.

\begin{tabular}{lcc}
\hline \multicolumn{1}{c}{ Variables } & $\begin{array}{c}\text { Dental Age } \\
\text { Mean (SD) }\end{array}$ & $\begin{array}{c}\text { BMI Value } \\
\text { Mean (SD) }\end{array}$ \\
\hline Gender & $10.57 \pm 2.42$ & $17.02 \pm 3.92$ \\
Boys & $10.60 \pm 2.44$ & $17.77 \pm 4.72$ \\
Girls & & \\
Chronological Age & $8.97 \pm 10.84$ & $16.08 \pm 3.37$ \\
8-10 years old & $10.84 \pm 1.24$ & $17.79 \pm 4.28$ \\
10-12 years old & $13.63 \pm 1.71$ & $19.70 \pm 5.17$ \\
12-15 years old & & \\
Dental Age & $8.22 \pm 0.57$ & $14.17 \pm 1.25$ \\
7-9 years old & $9.77 \pm 12.11$ & $16.45 \pm 3.37$ \\
9-11 years old & $12.11 \pm 0.45$ & $20.55 \pm 3.41$ \\
11-13 years old & $14.60 \pm 0.65$ & $21.58 \pm 4.82$ \\
13-15 years old & & \\
Body Mass Index (BMI) & $9.96 \pm 2.50$ & $16.82 \pm 4.46$ \\
Underweight & $9.70 \pm 1.28$ & $16.20 \pm 3.34$ \\
$\quad$ Normal / Ideal & $12.18 \pm 2.84$ & $19.51 \pm 5.37$ \\
Overweight & $12.71 \pm 2.44$ & $19.65 \pm 4.38$ \\
$\quad$ Obese & & \\
\hline
\end{tabular}

Table 4. Relationship between Body Mass Index and dental age.

\begin{tabular}{ccccc}
\hline Variables & $\begin{array}{c}\text { BMI Value } \\
\text { Mean (SD) }\end{array}$ & $\begin{array}{c}\text { Dental Age } \\
\text { Mean }(S D)\end{array}$ & p-value & r / $\mathbf{r}^{2}$ \\
\hline $\begin{array}{c}\text { Chronological Age } \\
8-10 \text { years old }\end{array}$ & $16.08 \pm 3.37^{\mathrm{a}}$ & $8.97 \pm 10.84^{\mathrm{a}}$ & $<0.001^{*}$ & $0.734 / 0.538$ \\
$10-12$ years old & $17.79 \pm 4.28^{\mathrm{a}}$ & $10.84 \pm 1.24^{\mathrm{a}}$ & $<0.001^{*}$ & $0.920 / 0.846$ \\
$12-15$ years old & $19.70 \pm 5.17^{\mathrm{a}}$ & $13.63 \pm 1.71^{\mathrm{a}}$ & $0.029^{*}$ & $0.603 / 0.363$ \\
Overall & $17.38 \pm 4.29^{\mathrm{a}}$ & $10.58 \pm 2.40^{\mathrm{a}}$ & $<0.001^{*}$ & $0.668 / 0.446$ \\
\hline${ }^{\mathrm{a} N o r m a l i t y ~ t e s t ~-~ S h a p i r o-W i l k ~ t e s t ; ~ * P e a r s o n ~ c o r r e l a t i o n ~ t e s t: ~} \mathrm{p}<0.05$ significant. & &
\end{tabular}

\section{Discussion}

In this study, dental age was measured using the Demirjian method. This method is conducted by observing root and crown development stages of the seven left mandibular permanent teeth through panoramic radiographs [6]. In contrast to Star methods, which require CBCT radiographs and Kohler method, which requires the presence of third molars, the Demirjian method is more preferred because the criteria of each stage is clearly described, which is based on the shape and proportion of root length. Besides, this method is quite simple since it only requires reviewing panoramic appearances [13,14].

Body Mass Index (BMI) was selected as the method to measure body status because this method is not only simple but also non-invasive and less expensive. In contrast to other methods such as Rohrer index, BMI only rely on the information of height and weight data that can be obtained with simple equipment with accurate results [15].

Based on gender, the mean BMI in females reached 17.77 , followed by 10.60 years in dental age, whereas in males, the mean BMI was only 17.02, followed by 10.57 years in dental age. This result showed that females were more advanced in dental age and had greater BMI than males. Dental age differences between 
males and females, where accelerated dental development in males ranged from 0.09-2.83 years, while females ranged from 0.72-3.33. Females are more likely to enter a growth spurt period earlier than males (females: 10 years old, males: 12 years old). The growth spurt is a period when the growth occurs more rapidly and the tooth undergoes movement more actively [9,16].

Based on chronological age, as BMI increased, dental age was more advanced, $53.8 \%$ in the $8-10$ age group, $84.6 \%$ in the $10-12$ age group, and $36.3 \%$ in the $12-15$ age group. Overall, statistical tests results also showed a significant correlation between BMI values with dental age in which the dental age was more advanced, $44.6 \%$ as BMI increased $(\mathrm{p}<0.05)$. The obese group had an average dental age up to 12 years old, while the underweight group was only nine years old. Advanced dental age accompanied by increased BMI indicating dental age acceleration. This finding supports the evidence that overweight and obese children experience accelerated dental development compared to their normal and underweight peers. Dental age was more advanced as BMI increased. Conversely, as BMI decrease, the dental age becomes delayed. Delayed deciduous and permanent tooth emergence in children with under-nutrition and, subsequently, low body mass $[7,17]$.

Previous studies have been conducted to validate the effect of BMI on dental development. Correlation between childhood obesity and dental maturation reported an accelerated dental maturation occurred in overweight and obese children. Teenagers and pre-teens body size have a significant impact on the dental growth and development wherein overweight and obese children were more advanced in dental development compared to their normal and underweight peers. Malnourished children are slightly experiencing a delayed eruption of deciduous and permanent teeth compared to normal-weight children [9,18,19].

The main cause of the dental age acceleration in children with a high BMI value has not been thoroughly and scientifically known yet. Accelerated dental maturation allegedly associated with increased levels of free IGF-1 (Insulin-Like Growth Factor-1), IGF-Binding protein-1 and GH-Binding protein (a main circulating growth factor). Obese children have been shown to have decreased levels of growth hormone resulting in increased secretion of free IGF-1, which plays an essential role in accelerating the growth process. It is assumed that free IGF-1 will indirectly affect craniofacial growth and development, including dentalrelated growth $[8,20]$.

The present study proved the relationship existed between Body Mass Index and dental age. Accelerated dental maturation indicating the peak height velocity and pubertal growth spurt occurs earlier. The appropriate time for initiating orthodontic treatment is when a person has entered a growth spurt period where the tooth movement is more active. Overweight and obese patients may require earlier treatment due to dental maturation occurs more quickly; otherwise, treatment for underweight patients may be delayed due to dental maturation occurs slowly. Seeing the relationship between Body Mass Index and dental age could affect orthodontic treatment, BMI data is important to consider before determining orthodontic treatment time [1].

\section{Conclusion}

There was a linear correlation between increased BMI with accelerated dental age in orthodontic patients aged 8-15 years. Advanced dental age accompanied by increased BMI indicating dental age acceleration. Conversely, decreased BMI indicating delayed in dental age. BMI value and dental age can be considered in determining orthodontic treatment time.

\section{Authors' Contributions}




$\begin{array}{lll}\text { EE } & \text { (D) 0000-0002-1760-2409 } & \begin{array}{l}\text { Supervision, Conceptualization, Methodology, Formal Analysis, Resources, } \\ \text { Validation and Writing - Review and Editing. }\end{array} \\ \text { SM } & \text { (D) 0000-0003-4678-5272 } & \text { Formal Analysis, Resources and Writing - Review and Editing. } \\ \text { FHA } & \text { (D) 0000-0003-4819-4820 } & \begin{array}{l}\text { Formal Analysis and Writing - Review and Editing. } \\ \text { AR }\end{array} \\ \text { (D) 0000-0002-0285-550X } & \begin{array}{l}\text { Methodology, Investigation, Formal Analysis, Data Curation and Writing - } \\ \text { Original Draft Preparation. }\end{array} \\ \text { All authors declare that they contributed to critical review of intellectual content and approval of the final version to be } \\ \text { published. }\end{array}$

\section{Financial Support}

None.

\section{Conflict of Interest}

The authors declare no conflicts of interest.

\section{Acknowledgements}

The authors are grateful to Clinical Orthodontics Center, Dentamedica Care Center Clinic and Dental Hospital of Hasanuddin University for allowing us to obtain data during this study.

\section{References}

[1] Bjork A, Helm S. Prediction of age of maximum pubertal growth in the body height. Angle Orthod 1967; 37(2):13443.

[2] Siswanto F, Sjahruddin L. Correlation between mandible length and dental calcification stages on the Deutero-Malay group children aged 8-16 years. J Dent Indones 2010; 17(1):1-8.

[3] Proffit WR, Henry WF Jr, Sarver DM. Contemporary Orthodontics. 4th ed. St. Louis: Mosby Elsevier; 2007.

[4] Johnston FE, Hufham HP Jr, Moreschi AF, Terry GP. Skeletal maturation and cephalofacial development. Angle Orthod 1965; 35:1-11.

[5] Jurca A, Lazar L, Pacurar M, Bica C, Chibelean M, Bud E. Dental age assessment using Demirjian method - a radiographic study. Eur Sci J 2014; 10(36):51-60.

[6] Demirjian A, Goldstein H, Tanner JM. A new system of dental age assessment. Hum Biol 1973; 45 (2):211-27.

[7] Anbiaee N, Rashed Mohassel A, Bagherpour A. The relationship between body mass index and dental development by Demirjian's method in 4 to 15-year-old children in Mashad. J Dent Mater Tech 2013; 2(3):82-5. https://dx.doi.org/10.22038/jdmt.2013.1048

[8] Sadeghianrizi A, Forsberg CM, Marcus C, Dahllöf G. Craniofacial development in obese adolescent. Eur J Orthod 2005; 27(6):550-5. https://doi.org/10.1093/ejo/cjio48

[9] Hilgers KK, Akridge M, Scheetz JP, Kinane DE. Child obesity and dental development. Pediatr Dent 2006; 28(1):1822.

[10] Flores-Mir C, Mauricio FR, Orellana MF, Major PW. Association between growth stunting with dental development and skeletal maturation stage. Angle Orthod 2005; 75(6):935-40.

[11] Bagherian A, Sadeghi M. Assessment of dental maturity of children ages 3.5 to 13.5 years using the Demirjian method in Iranian population. J Oral Sci 2011; 53(1):37-42. https://doi.org/10.2334/josnusd.53.37

[12] Health Research and Development Agency. National report 2007: Basic Health Research. Republic of Indonesia: Ministry of Health; 2007.

[13] Liversidge HM. Permanent tooth formation as a method of estimating age. Front Oral Biol 2009; 13:153-7. https://doi.org/10.1159/000242409

[14] Chen F, Terada K, Hanada K. A new method of predicting mandibular length increment on the basis of cervical vertebrae. Angle Orthod 2004; 74(5):630-4.

[15] Centers for Disease Control and Prevention. Body Mass Index: Considerations for Practitioners. USA: Department of Health and Human Services Centers for Disease Control and Prevention; 2009.

[16] Gaethofs M, Verdonck A, Carels C, de Zegher F. Delayed dental age in boys with constitutionally delayed puberty. Eur J Orthod 1999; 21(6):711-5. https://doi.org/10.1093/ejo/21.6.711

[17] Zangouei-Booshehri M, Ezoddini-Ardakani F, Aghili HA, Sharifi A. Assessment of the relationship between body mass index (BMI) and dental age. Health 2011;3(5):253-7. https://doi.org/10.4236/health.2011.35045

[18] DuPlessis EA, Araujo EA, Behrents RG, Kim KB. Relationship between body mass and dental and skeletal development in children and adolescents. Am J Orthod Dentofacial Orthop 2016; 150(2):268-73. https://doi.org/10.1016/j.ajodo.2015.12.031 
[19] Gaur R, Kumar P. Effect of undernutrition on deciduous and permanent tooth emergence among Rajput children of Shimla District of Himachal Pradesh, India. Am J Phys Anthropol 2012; 148(1):54-61. https://doi.org/10.1002/ajpa.22041

[20] Argente J, Caballo N, Barrios V, Pozo J, Muñoz MT, Chowen JA, et al. Multiple endocrine abnormalities of the growth hormone and insulin-like growth factor axis in prepubertal children with exogenous obesity: effect of short and long term weight reduction. J Clin Endocrinol Metab 1997; 82(7):2076-83. https://doi.org/10.1210/jcem.82.7.4089 